\title{
THE ECONOMICS OF PAPER CONSUMPTION IN OFFICES
}

\author{
Iqtidar Ali SHAH ${ }^{1 *}$, Sohail AMJED ${ }^{2}$, Nasser Alhamar ALKATHIRI ${ }^{3}$ \\ 1, 2, 3 Department of Business Administration, College of Applied Sciences, Salalah, \\ Ministry of Higher Education, Sultanate of Oman
}

Received 09 January 2018; accepted 08 October 2018

\begin{abstract}
This paper explores the factors potentially responsible for the overconsumption of office paper and estimates the adverse environmental and economic impact of overconsumption. Data were collected from the employees of selected higher educational institutions in Oman. Technical factors, workplace environment, printing preferences and lack of awareness were found the main cause of overconsumption. Environmental and economic impact of the paper was estimated from the actual amount of paper consumed using standard formulas from literature. The institutions have used 5,200 reams (13 tons) of $80 \mathrm{gm} \mathrm{A4}$ size paper in one year. The economic cost of the paper was 7,800 OMR (20,280 US\$). The environmental impact estimated are: cutting of 312 trees, 73,970 Ibs of $\mathrm{CO}_{2}$ gas emission, 144,742 KWh of energy consumption, solid waste produced 29,614 lbs and 247975 gallons of water were wasted. Changing printing preferences, a significant amount of economic and environmental resources to the tune of $44.8 \%$ can be saved.
\end{abstract}

Keywords: computer technology, environmental and economic cost, Oman, printing, paper consumption.

JEL Classification: Q00, Q51, Q53, D12.

\section{Introduction}

World over organizations are looking for the strategies and tactics to improve their financial efficiency by seeking ways to reduce operating cost. The use of IT is one of the best ways adopted in most of the organizations to curtail operating cost by replacing office paper which saves millions of dollars (Sarantis, 2002). However, significant evidence exists that IT use in the workplace such as computers, internet or printer, world wide web and email has increased paper consumption (Mukete, Sun, Zama, \& Monono, 2016; York, 2006; Sellen \& Harper, 2002) which has in turn increased companies' cost of doing business (such as purchasing, storage, lost documents, postage, waste) and labor inefficiency (Sarantis, 2002). Hujala (2011) and Peters (2003) also confirmed that a growing number of personal computers in offices has increased paper consumption. Thus, the dream of paperless office has not yet become

*Corresponding author. E-mail: iqtidar.sal@cas.edu.om 
a reality (King \& Toland, 2014) as paper consumption has continued to rise over the last few decades (McCormack, 2011). An increasing amount of paper consumption has also a significant impact on the environment and human health (Andrés, A. Zentner, \& J. Zentner, 2014; Smith, 2011). The environmental impact of paper consumption includes overconsumption of resources, deforestation, air, water and land pollution. The paper industry is among the world's largest generators of air and water pollutants, waste products and the gases that cause climate change. It is also one of the largest user raw materials including fresh water, energy and forest fibers (Sharma, 2014). For example, production of one ton of copy paper uses 11,134 kWh of electricity, produces 19,075 gallons of wastewater, 2,278 lb of solid waste, $5,690 \mathrm{lb}$. of greenhouse gases and required 3 tons of wood (FAO, 1997). Impact of paper on human health include both occupational hazards and impacts on air, soil, and water that affect the health of communities in the vicinity of pulp and paper mills (Soskolne \& Sieswerda, 2010). The health impact includes various types of cancer due to the dioxins released in the production of paper (Thompson, Swain, Kay, \& Forster, 2001; Sumathi \& Hung, 2006, World Health Organization, 2016).

Unsustainable consumption and production patterns are the main factors influencing unsustainability (Jonkute, 2015). In the case of paper industry, the literature focuses more on the production side i.e. paper recycling and technologies which can reduce the negative environmental impact and economic cost. However, technology improvement, which has increased production efficiency, is not sufficient to considerably reduce the use of natural resources (Sophia, 2013). Industrial development has reduced the environmental impact during the last 25 years but at the same time production as well as consumption has increased by the same levels, which erodes the environmental benefits of the technological advances: i.e. the rebound effect (Throne, Sto, \& Strandbakken 2007). Similarly, efficient production decreases prices and increases consumption (Niinimäki \& Hassi, 2011). Thus, technological approaches are not sufficient to achieve sustainable development without focusing on consumption. Therefore, it is important to examine the factors affecting paper consumption. There are various factors which have increased the paper consumption in the workplace. Sopha (2013) explored the behavioral factors of paper consumption which include habit, intention, attitude, personal norms and situational influence. However, there are many other factors responsible for over-consumption of paper such as organization's requirements, technical factors related to the use of technology and lack of employees' awareness regarding the negative impact of paper use which has not been explored.

The aim of this paper is to explore the potential factors responsible for overconsumption of paper in organizations and estimate its impact on environmental degradation and economic cost. More specifically, to investigate the causes and effects of various common practices on the excessive use of paper in the educational institutions in Dhofar region of Oman and explore various ways, techniques and strategies to reduce paper use in organizations in order to improve their efficiency by saving their resources and to contribute to environmental protection. Moreover, to answer the questions of how efficiently paper is used for printing purposes in organizations? What are the causes of overconsumption of paper in organizations? What are the impacts of overconsumption of paper on environment and economic cost? And how overconsumption or wastage of paper can be reduced in organizations? 
This paper contributes to the body of existing knowledge by identifying and analyzing potential factors that influence paper uses and estimates the impact of paper consumption and wastage on the operating cost of the organization and the environment. Overall the paper contributes to the current knowledge of sustainability by analyzing current practices related to paper consumption.

The rest of the paper is organized as follow: Section 1 is the account of existing literature related to the study, section 2 presents the conceptual framework, the methodology is explained in section 3, results are given in section 4, discussion and recommendations is carried out in section 5 and the last section concludes the paper.

\section{Literature review}

There is significant evidence reported in various reports that paper use and paper wastage at the workplace has increased due to the use of office technology such printer, internet, email etc. The latest report by Upstate Medical University (2016) confirmed that paper product usage in America has increased from 92 million tons to 208 million (126\% increase) in the last 20 years. The report also confirmed that $45 \%$ of the paper printed in offices are ended up trashed by the end of the day, resultantly, trillion sheets of paper are wasted every year worldwide. Another report by SC Technology Group (2015) also pointed out the overconsumption of paper and reported that two million pages are printed every minute across Europe, the Middle East and Africa. The overall global paper production is more than 350 million tons annually (Smith, 2011). Looking into the wastage side, Hesseldahl (2008) investigated that half of all documents printed are discarded within 24 hours. Inefficient and excessive utilization of paper has an adverse effect on an organization's cost, efficiency as well as the environment. The economic cost and environmental concerns related to overconsumption of paper, causes/factors of overconsumption of paper and strategies to reduce overconsumption of paper are reviewed below.

\subsection{The organization efficiency and cost: argument for paper reduction}

The suboptimal use of IT technologies increased the use of paper in organizations. Resultantly, the operation costs increased. The printing costs of Bank of America Corp. were running at $\$ 70$ million to $\$ 90$ million a year because of 90,000 printers it owned - one for every two employees (Tam, 2004). The financial cost of paper is not only just purchasing the paper but also costs of storage, documents security, postage, document obsolescence, and labor inefficiency. According to a report, reducing dependency on paper usage at the office can result in higher efficiency, increased productivity and savings for the organization (Paperless Project, 2013). Fujitsu (2001) estimated in a case study of an organization that in real estate processing time was reduced from 46 days to 3 hours by implementing a scanning system with electronic document access.

The cost impact of using paper in an organization is calculated by Standard Chartered Bank (2010) which is given in Table 1 below: 
Table 1. Cost impact of paper consumption (source: Standard Chartered Bank, 2010)

\begin{tabular}{|l|l|c|c|}
\hline Paper Consumption & \multicolumn{1}{|c|}{ Item used } & Cost (US\$) \\
\hline \multirow{3}{*}{$\begin{array}{l}\text { 140 ton of paper } \\
\text { (56000 reams) of A4 } \\
\text { paper per year: }\end{array}$} & Paper & $\begin{array}{l}\text { Depreciation for a mid-level } \\
\text { corporate Laser Printer }\end{array}$ & $\begin{array}{l}\text { Toner Cost for paper print- } \\
\text { ing with double sides }\end{array}$ \\
\cline { 2 - 4 } & $\begin{array}{l}\text { The total cost of electricity } \\
\text { consumed (14,933 kW-hr) }\end{array}$ & 910 \\
\cline { 2 - 4 } & Total printing cost & 3,005,777 (3 million \$ per year) \\
\hline
\end{tabular}

\subsection{Environmental impact: argument for paper reduction}

The paper has become a bottleneck and a clear impediment for organizations that are looking for greener IT. It is a well-recognized fact that the excessive use of paper in the workplace has substantial effects on the environment including deforestation, greenhouse gasses emission, energy consumption, solid waste, wastewater and water contamination. The life of a paper starts with tree cutting in a forest and ends with the burning, solid waste or recycling. The most harmful part is the process of paper production which consumes a lot of energy, water, Sulphur Oxide (SOX) and $\mathrm{CO}_{2}$ emission.

The environmental impact of using paper in the organization is calculated by Standard Chartered Bank (2010) is given in Table 2.

Table 2. Environmental impact of paper consumption (source: Standard Chartered Bank, 2010)

\begin{tabular}{|l|l|c|l|}
\hline Production & \multicolumn{1}{|c|}{ Description } & Amount & \multicolumn{1}{|c|}{ Equals to } \\
\hline \multirow{4}{*}{$\begin{array}{l}\text { 1 ton A4 paper } \\
\text { (400 reams of } \\
\text { A4 paper) }\end{array}$} & Wood Requirement & 3.47 ton & 24.29 trees \\
\cline { 2 - 4 } & Energy Requirement & 38.7 million buts & $\begin{array}{l}1 / 2 \text { year of the energy of a US house- } \\
\text { hold }\end{array}$ \\
\cline { 2 - 4 } & Solid Waste Produced & $2,283 \mathrm{Ibs}$ & 0.08 fully loaded garbage trucks \\
\cline { 2 - 4 } & Emissions & $5868.8 \mathrm{Ibs}$ & $1 / 2$ year emission for a car \\
\cline { 2 - 4 } & Water Requirements & 20,520 gallons & 0.03 Olympic sized swimming pool \\
\cline { 2 - 4 } & Waterborne Wastage & $109.9 \mathrm{Ibs}$ & - \\
\hline
\end{tabular}

\subsection{Causes of overconsumption of paper}

Concerns about overconsumption of paper in organizations have been raised due to its negative impacts on the environment, economic cost and efficiency. There are few papers and reports which have investigated the causes of overconsumption of paper. Sophia (2013) investigated that paper consumption behavior begins with the appreciation of situational factors, which influences norms, which in turn forms a habit. The habit subsequently influences paper consumption behavior and thus she concluded that paper consumption behavior is more habitual. Kazanci (2015) also conducted research on university students to investigate the preferences of university students for reading from a printed text or from a digital screen 
and confirmed that majority of the students prefer traditional printed paper instead of the digital screen for their reading activities. Webster (2012) identified several factors of using more paper in organizations such as workers used paper due to their old habits, requirement of hard copy for file, submission of documents in paper form, filling forms by hand, requirements for physical signature (lack of comfort with electronic signatures), and the need to print documents for use in the field where it is difficult to take along a PC. Similarly, the paper is widely, heavily and preferably used in organizations worldwide because of its physical properties and affordances such as thin, light, porous, opaque and flexible which is easy to grasp, carry, fold, and write. (Jenkin, Webster, \& McShane, 2011; Sellen \& Harper, 2002; York, 2006). King and Toland (2014) compared the affordances and limitations of paper with Digital technologies such as PCs, e-reader and iPad and found that Digital technologies such as PCs and e-readers have not been able to minimize the paper because they do not match the key affordances of paper.

\subsection{Strategies for minimizing misuse/overuse of paper consumption}

To control paper over consumption or to minimize paper consumption by office workers in workplace, various strategies have been proposed by researchers or some international organizations such as WWF (2015), Federal Electronic Challenges (2012), Sustainability Victoria (2011), Preton (2010), Standard Chartered Bank (2010), McCool (2008) and Sarantis (2002) which are reviewed below.

\subsubsection{Efficient use of paper}

There are various ways and methods to control overused or misused of paper. For example, printing/copying onto both sides of a paper can save up to $30 \%$ of paper. Duplexing saves not only paper cost but storage, mailing cost and energy. N-Up printing "multiple pages per sheet" an option within printing preferences, is an effective way of reducing paper consumption. Reducing margin is also a significant way adopted in some organizations to reduce paper consumption. By reducing the margins, $14 \%$ less paper is used as compared to normal margin. Reducing the paper margins to 0.75 " or 0.5 " can save a significant amount of paper. According to a study carried out by the Penn State University (2000), reducing margins to 0.75 " on all sides results in a total reduction of paper usage of $4.75 \%$. The Penn State University uses 950,350 reams in the year 2000. If the paper used with 0,75 margins are applied, 905,208 reams can be used. Thus, 45,142 reams can be saved with a total saving of $112,855 \$$ (paper cost $2.5 \$$ per ream). Other printing options such as of font size, font types and line space can be used to reduce the overconsumption of paper. Reducing the font size to 10 points will decrease the amount of paper. Even reducing from 12 points to 11.5 points will shrink document about 5\%. Paper and ink can be saved by using different fonts. An analysis performed by the University of Wisconsin's IT Department concluded that font type "Century Gothic" and font size 11 was the best for saving ink and toner. Other ink saving fonts type and size includes "Times New Roman - 12", "Calibri - 11" and "Verdana - 11". Reducing line space to single space can reduce the amount of paper. If we change the line spacing of 1.0 to 0.95 , we can make document $5 \%$ shorter. Similarly, the use of print preview 
function before printing can avoid mistakes and can reduce paper use. Similarly, on-screen proofreading and auditing also reduce paper consumptions. The creation of PDF (Portable Document Format) can reduce paper use. PDF is a global printing standard. If a hard copy of a document is not required, a PDF is an effective alternative to printing as a means of archiving or sharing a document. Another strategy of "image reduction" is used to reduce paper consumption. For example, when copying a book, two original pages on to one side of the copied sheet can save paper by 50\%. The use of the blank sides of unneeded single-sided copies (scrap paper) for printing drafts or writing notes can save more paper.

\subsubsection{Printing policy}

In order to reduce the negative impacts of paper use on the costs and environment, it is imperative that each organization has a policy for "paper use and printing". Various printing and copying behavior of employees indicate that there is a lack of printing policies in organizations. Most of the employees print the paper and then forget to take printout from the printers, which results in wastage of paper. According to a survey, up to $15 \%$ of the pages are being left unclaimed at the printer and then subsequently discarded (SC Technology Group, 2015). This is because of no limits on using paper printing in most of the organizations. Fixing paper limits/quota for employees can reduce the wastage (EPA, 2001). A comprehensive printing policy for user authentication, tracking, quotas, and limitations on what employees can and cannot print, will significantly reduce the misuse and overuse of paper. Some of the organizations have banned printing emails and internet content because this is wasteful. They asked their employees to use folders and archiving functionality in e-mail application to organize and view messages. According to $\mathrm{McCool}$ (2008), the amount of waste generated by Web printouts is profoundly provoking. The cost and environmental impact of paper can be reduced by using thinner paper. For example, paper with a weight of 60 grams has $20 \%$ more cost than paper with 50 grams. Similarly, 100 grams paper cost is $20 \%$ more than 80 grams paper. Most offices can transfer paperwork online. For example, a college/university can provide online time sheets for all campus employees/student/ workers, online admissions, online course registration, correspondence via email etc. Use of electronic purchase and invoices can also reduce paper use. For example, Bell Atlantic saved 29 tons of paper and more than $\$ 60,000$ by expanding the use of electronic purchasing orders and invoices.

\subsubsection{Printer default settings}

The organizations' printing policy can be easily implemented by setting up printers to print with smaller margins, single line space, smaller font size, smaller font type, double-sided, black and white as an automatic default rather than to check files and paper of individual employee to make sure that printing policy has been followed. Egebark and Ekström (2013) conducted a research using the printer default from simplex to duplex in large Swedish universities to see the effect on paper consumption. They observed 25 printers on daily basis for the period of three months and concluded that duplex default of printers reduced paper consumption by $15 \%$. They also found that the more conventional method of encouraging people to save resources has no impact at all. 


\subsubsection{Follow me printing}

"Follow me printing" is another way recently used in organizations to reduce paper waste and secure printing documents. Using "follow me printing", a user can initiate a print job from any workstation and can execute the print job when physically present at the desired printer after successful authentication. In a standard printing environment, a user sent directly to the printer for immediate printing. This results in wasted paper and toner when printing is forgotten and not collected.

\subsubsection{Awareness and training}

The employees' awareness about the impact of paper on organization's cost and the environment is essential because it can decrease the use of paper. However, there is lack of evidence in the literature to show that organizations have provided some kind of training or awareness program to their employees for the efficient use of paper in offices. Some tips have been developed by organizations regarding how to use paper efficiently (Standard Chartered Bank, 2010; Minnesota Pollution Control Agency, 2016; WWF, 2015; Federal Electronic Challenges, 2012; Repaper Project (n.d.).

\subsubsection{Use of electronic textbooks}

The use of tablets/iPads and electronic textbooks have grown rapidly due to which a new debate on the efficiency, effectiveness and impact of digital materials in comparison to print materials have emerged. The debate mainly focused on a question that is digital technologies such as tablets, iPad and electronic textbooks are more environmentally friendly than paper? King and Toland (2014) examined the use of tablet devices to determine whether they can make a significant impact on paper consumption and found that the use of tablet devices such as the Apple iPad has the potential to reduce paper consumptions particularly in higher education establishments who are traditionally heavy users of paper. They further found that the iPad has not been able to reduce paper consumption to the level expected but it has been significantly better than other digital technologies in reducing paper consumption as it is well perceived, portable, easy to use, and its screen is well suited for reading documents. AL-Qahtani (2012) explored the potential of using tablet devices and investigated that iPad reduce the use of paper in the workplace. Moberga, Johanssonb, Finnvedena, and Jonssonc (2010) investigated the potential environmental impacts of printed newspaper paper and tablet e-paper newspapers and found that the printed newspaper, in general, had a higher energy use, higher emissions of gases contributing to climate change and several other impact categories than the tablet e-paper newspaper. They concluded that tablet e-paper has the potential to decrease the environmental impact of newspaper consumption.

\subsubsection{Document Management System}

Document Management System (DMS) is another fast practical alternative way to reduce the paper dependency of organizations. This system enables users to easily scan documents, locate files quickly and share documents with others fastly and securely which reduce companies cost (Ranko, Berislav, \& Antun, 2008). Krishnan and Subramanian (2015) evaluated the 
carbon-reducing impact of a DMS and found that DMS helps to reduce carbon footprint by more than $1400 \mathrm{~kg}$ per day. Susanty, Thamrin, Erlangga, and Cucus (2012) investigated that the concept of paperless office is possible by adopting the DMS by organizations.

\section{Conceptual framework}

There are many factors/causes which influence paper usage in organizations. In this paper, four factors have been considered as explained in Figure 1 below:

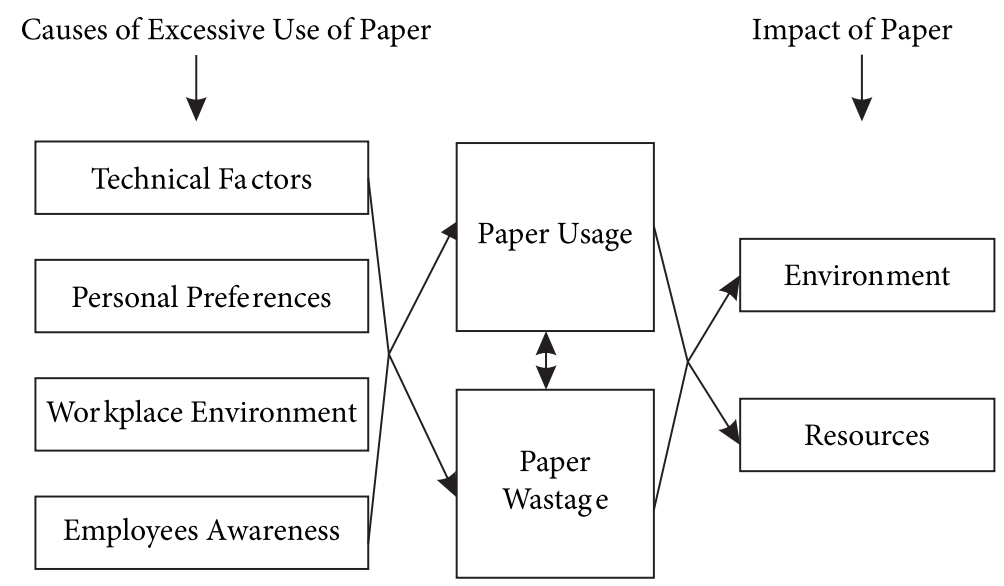

Figure 1. Conceptual framework

The overconsumption of paper in an organization depends on many factors such as technical factors (McCool, 2008), workplace environment (Sarantis, 2002), organization requirements and policies (Jenkin, Webster, \& McShane, 2011), employee’s personal preferences (Jenkin et al., 2011), employees' awareness and training about the usage of paper (WWF, 2015), etc. Significant evidence shows that paper is misused and overused in organizations due to aforementioned factors which are a challenge for organizations and world community because of its worse effect on resources and the environment. The factor "organizations' requirements and policies" regarding the usage of paper is out of the scope of this paper because many legal issues are involved due to which it is not possible for an employee and organizations to reduce dependency on paper. This paper is limited to the four factors i.e. technical factors, workplace environment, employees' personal preferences, employee's awareness and training. These factors are chosen because organizations can control the overuse or misuse of paper if they realized that how these factors contribute in the overconsumption of paper without compromise of their organizations' policies, legal issues and any additional costs. There is a relationship between misuse/overuse of paper and technical factors because there are many employees who are not familiar with the use of printers or carelessly printing documents. In many offices, printers have also some technical faults. Due to these technical factors, paper is overused. Similarly, the workplace environment of the organization has also 
an impact on the use of paper. For example, many employees keep printed documents in their personal record because they do not trust their colleagues. There are employees who keep printed documents in safe custody because they do not trust the technology and they think that hard copies are safer than the soft copies. Resultantly, the use of paper increased due to the inappropriate workplace environment. The relationship between overconsumption of paper and people's preference for using various options of printing and paper cannot be ignored. Due to the digital technology various option of line space, font types, font size, paper margin etc. is available to the employees which have significantly increased the use of paper in organizations. Similarly, some employees do not know the use of technology and its various options; they do not know the impact of paper usage on organization resources and the environment. Thus, due to lack of awareness and training to employees, the paper is overused or misused in the organization. There is also a bidirectional relationship between paper usage and paper wastage. The more employees use paper, the more wastage will be and vice versa. There is also adverse impact of paper usage and paper wastage on resources and the environment. The overall uses of paper in offices have a negative impact on the organization's efficiency, cost and environment. This paper is limited to two variables i.e. organization cost and the environment.

\section{Methodology}

All the three higher education institutions from Salalah city of Dhofar region of the Sultanate of Oman were surveyed which include College of Applied Sciences, Technical College, and Dhofar University. The survey was personally administrated by the researchers. Informed consent was obtained from the educational institutions through the official channel prior to starting the survey and the confidentiality and anonymity of the responses were ensured. More than 200 questionnaires in both Arabic and English language were distributed in person to the academic and administrative staff of the participating educational institutions. All most all academic and administrative staff were using papers. However, data were obtained from those who were available in their offices at the time of survey using a convenience sampling procedure. Total 179 completed questionnaires were collected back in person of whom 176 questionnaires were usable.

\subsection{Survey instrument}

A questionnaire was developed in the Arabic language to obtain data about the paper consumption and factors potentially responsible for the paper wastage in the educational institutions in Dhofar region of the Sultanate of Oman. The official language of Sultanate of Oman is Arabic but English is widely used as a second language. The questionnaire was translated into the English language for non-Arabic expatriate employees by using the standard method of "back translation". The questionnaire includes questions about the demographics of the respondents and six other variables; namely, (i) approximate weekly paper usage (ii) approximate weekly paper wastage (iii) respondent's perception of the workplace environment (iv) technical factors (v) personal printing preferences and (vi) employee's awareness about the 
environmental degradation due to paper usage. The questionnaire was initially sent to the selective academicians for validity and technical evaluation and suggestions for improvement prior to finalization. The suggestions for improvement in the instrument from the academic staff were incorporated in the first round. As a second round, the questionnaire was distributed for pilot testing and the responses were analyzed. After satisfying the entire prerequisite to conducting the survey the questionnaire was distributed for data collection.

We included two explained variables and four explanatory variables in the questionnaire. The explained variables include paper usage and paper wastage. Explanatory variables include technical factors, workplace environment, personal preferences, and employee's awareness. Approximate weekly paper usage is measured as 3 items five-point ordinal scale. The variable contains questions such as (i) how many pages you print for your email correspondences on average per week? (ii) How many pages you print from internet contents on average per week? (iii) How many pages you print/photocopy other than email and internet contents on average per week? Similarly, approximate weekly paper wastage was measured using 3 items five-point ordinal scale. The variable contains questions such as (i) how many pages are usually wasted when you print/copy the paper on average per week? (ii) How many pages do you put in shredder after reading/using on average per week? (iii) How many pages do you put in the dustbin after reading/using on average per week? The potentially explained variables were measured by using five scale ordinal ranges of the number of pages.

Four explanatory variables were included as potential determinants of the paper usage and paper wastage. Technical factors were measured by 3 items using a five-point Likert scale. The variable contained items such as (i) How frequently are paper wasted due to malfunctioning of printing equipment? (ii) How frequently are paper wasted due to unintended printing command? (iii) How frequently are paper wasted due to unfamiliar printing equipment? Workplace environment with reference to the paper usage was the second explanatory variable measured as 5-point Likert scale including 4 questions such as (i) I maintain a personal record of documents in hard copies due to an insecure office environment (ii) I keep a record in the form of printed documents in anticipation of future problems. (iii) I keep printed documents in safe custody as I can't trust the technology. (iv) I fear, anytime someone can accuse me and I would need documented evidence to prove my stance. The third explanatory variable "printing preferences" was measured by 5 items using five points Likert scale. The questions include (i) I prefer to print on one side of the paper. (ii) I prefer high-quality paper for printing documents (ii) I prefer wide margin for printing documents (iv) I prefer clear and large font style for printing documents (v) I prefer the line spacing greater than 1 line for printing documents. Finally, the employees' awareness about the environmental degradation due to paper usage and wastage was measured as 6 items using five points Liker scale. The questions include (i) I have learnt about the negative effects of paper usage on environment through conferences or public talks (ii) I have read printed material about the negative impact of paper usage on the environment (iii) I have learnt through social media about the negative environmental impact of paper usage (iv) I have watched television program/documentary about the negative impact of the paper usage on environment (v) I have been informed by my organization about the value of paper I use (vi) I have been trained/motivated by my organization to be efficient in paper use. The reliability of the variable was tested using Cronbach's Alpha values. 


\subsection{Model development}

We included two explained variables in this paper and the parameter coefficients were estimated through two separate regression equations. The relationship between the considered variables is expressed as the following general models.

$$
\begin{aligned}
& P U=f(P W, T F, W P, P P, E A) ; \\
& P W=f(P U, T F, W P, P P, E A),
\end{aligned}
$$

where $P U$ is approximate weekly paper usage by the respondent individually. $P W$ is the approximate weekly paper wastage by the respondent individually. $T F$ is the technical factors potentially responsible for paper usage and excessive printing. WP is the workplace environment, $P P$ is personal preferences for printing and $E A$ is employee's awareness about the adverse environmental effect of paper usage. The paper usage and paper wastage were interchangeably used as explained variables in one equation and explanatory variable in other equation. We argue that paper usage causes paper wastage and simultaneously paper wastage cause excessive paper usage. Therefore, we expect a bidirectional causation. We specify the following regression equations to estimate the parameters.

$$
\begin{aligned}
& P U=\beta_{0}+\beta_{1} P W+\beta_{2} T F+\beta_{3} W P+\beta_{4} P P+\beta_{5} E A+\varepsilon ; \\
& P W=\beta_{0}+\beta_{1} P U+\beta_{2} T F+\beta_{3} W P+\beta_{4} P P+\beta_{5} E A+\varepsilon,
\end{aligned}
$$

where $\beta_{0}$ the constant and $\beta_{1}$ to $\beta_{5}$ are the parameter coefficients of explanatory variables and $\varepsilon$ is the residual error which is normally distributed.

To assess the negative impact of paper usage and wastage on the environment we used standard formulas to quantify the environmental impact of paper usage (Abramovitz \& Ashley, 1999; Standard Chartered Bank, 2010; Mueller, 2001; Repaper Project (n.d.); FAO, 1997). To achieve this objective first we estimated the paper usage and wastage by individual employees through the collected data and then the standard formulas are applied to calculate the corresponding values. The actual data of paper usage by the participating educational institutions was also collected to check the reliability of the estimates. On the basis of the estimated data about the paper consumption and paper wastage, we estimated the economic cost and the environmental impact.

\section{Results}

Overall the response rate was $88 \%$. Out of the usable responses, $60 \%$ were in Arabic language and $40 \%$ were in English. The 32\% of the respondents were female and $68 \%$ were male. The responses from the academic staff remained $40 \%$ of the total sample and the remaining $60 \%$ were from the administrative staff of the educational institutions. The average age of the respondents was 34 years. With regard to academic qualification $15 \%$ of the respondents reported school education $27 \%$ reported diploma, $32 \%$ reported graduation, and $15 \%$ reported master degree and $11 \%$ were PhDs.

The descriptive statistics is presented in Table 3. The results show that the average response of the paper usage is 2.26 which corresponds to the option 11-20 pages per week 
or more precisely 15 pages per week. Similarly, the average response of the paper wastage is more than two which has corresponding value 6-10 pages per week. The Cronbach's Alpha values indicate that our variables have internal consistency and the collected data is reliable for the statistical analysis.

Table 3. Descriptive statistics

\begin{tabular}{|c|c|c|c|c|c|c|c|}
\hline Variables & $\mathrm{N}$ & Minimum & Maximum & Mean & Std. Dev & $\begin{array}{c}\text { Cronbach's } \\
\text { Alpha }\end{array}$ & $\begin{array}{c}\text { No of } \\
\text { Items }\end{array}$ \\
\hline $\mathrm{PU}$ & 176 & 1.00 & 4.67 & 2.2595 & .76526 & 0.773 & 3 \\
\hline $\mathrm{PW}$ & 176 & 1.00 & 4.33 & 2.1080 & .80338 & 0.744 & 3 \\
\hline $\mathrm{TF}$ & 176 & 1.00 & 4.67 & 2.2443 & .71556 & 0.697 & 3 \\
\hline $\mathrm{WP}$ & 176 & 1.00 & 5.00 & 2.7159 & .95070 & 0.810 & 4 \\
\hline $\mathrm{PP}$ & 176 & 1.00 & 4.60 & 2.5716 & .92353 & 0.812 & 5 \\
\hline $\mathrm{EA}$ & 176 & 1.00 & 5.00 & 2.6051 & .96387 & 0.832 & 6 \\
\hline
\end{tabular}

The pairwise correlation matrix by using the Pearson method is presented in Table 4 . The Pearson correlation is widely used method to estimate the nature of linear relationship between the variables. A Pearson correlation is preferred over the alternate Spearman correlation method in cases where the relationship between the variable is assumed to be linear. When the relationship between variables is non-linear Spearman correlation method is desirable because it estimates the correlation with monotonic variation in data. Since we posit the relationship among the considered variables is linear, therefore we applied Pearson correlation method. The results show that paper usage has a ppositive link with paper wastage, technical factors, workplace environment and personal preferences. However, a

Table 4. Correlation matrix

\begin{tabular}{|l|l|c|c|c|c|c|c|}
\hline \multicolumn{2}{|c|}{ Variables } & $P U$ & $P W$ & $T F$ & $W P$ & $P P$ & $E A$ \\
\hline \multirow{2}{*}{ PU } & Pearson Correlation & 1.000 & $.700^{*}$ & $.588^{*}$ & $.419^{*}$ & $.465^{*}$ & $-.559^{*}$ \\
\cline { 2 - 8 } & Sig. (2-tailed) & & 0.000 & 0.000 & 0.000 & 0.000 & 0.000 \\
\hline \multirow{2}{*}{ PW } & Pearson Correlation & $.700^{*}$ & 1.000 & $.490^{*}$ & $.390^{*}$ & $.454^{*}$ & $-.565^{*}$ \\
\cline { 2 - 8 } & Sig. (2-tailed) & 0.000 & & 0.000 & 0.000 & 0.000 & 0.000 \\
\hline \multirow{2}{*}{ TF } & Pearson Correlation & $.588^{*}$ & $.490^{*}$ & 1.000 & $.315^{*}$ & $.354^{*}$ & $-.428^{*}$ \\
\cline { 2 - 8 } & Sig. (2-tailed) & 0.000 & 0.000 & & 0.000 & 0.000 & 0.000 \\
\hline \multirow{2}{*}{ WP } & Pearson Correlation & $.419^{*}$ & $.390^{*}$ & $.315^{*}$ & 1.000 & $.274^{*}$ & $-.242^{*}$ \\
\cline { 2 - 8 } & Sig. (2-tailed) & 0.000 & 0.000 & 0.000 & & 0.000 & 0.001 \\
\hline \multirow{2}{*}{ PP } & Pearson Correlation & $.465^{*}$ & $.454^{*}$ & $.354^{*}$ & $.274^{*}$ & 1.000 & $-.426^{*}$ \\
\cline { 2 - 8 } & Sig. (2-tailed) & 0.000 & 0.000 & 0.000 & 0.000 & & 0.000 \\
\hline \multirow{2}{*}{ EA } & Pearson Correlation & $-.559^{*}$ & $-.565^{*}$ & $-.428^{*}$ & $-.242^{*}$ & $-.426^{*}$ & 1.000 \\
\cline { 2 - 8 } & Sig. (2-tailed) & 0.000 & 0.000 & 0.000 & 0.001 & 0.000 & \\
\hline \multirow{2}{*}{${ }^{*}$ Correlation is significant at $1 \%$ level. (2-tailed) } & & & & \\
\hline
\end{tabular}


negative correlation is found between paper usage and employee awareness. Similarly, there is a positive relationship between paper wastage, technical factors, workplace environment and personal preferences. The correlation between employee awareness and paper wastage is negative. In all cases except paper usage and wastage the correlation coefficient values show the moderate correlation among the variables. Therefore, there is no issue of multicollinearity in the model.

\subsection{Regression results}

The results of the regression equation 1 are presented in Table 5. The results show that paper wastage and technical factors cause overconsumption of paper. The parameter coefficient of paper wastage and technical factors are statistically significant at $1 \%$ significance level. Workplace environment also causes paper usage and the results are significant at 5\% level. Personal printing preferences also cause excessive paper usage but the results are significant at $10 \%$ level. The negative value of beta corresponding to employee's awareness indicates that the lack of awareness causes excessive paper usage and the parameter coefficient is significant at $5 \%$ level. The inverse relationship between awareness and paper usage was expected. The significant value of F-statistics indicates that our model is consistent. The coefficient of determination and the adjusted value of the coefficient of determination indicates that the $60 \%$ of the variation in the dependent variable is explained by the independent variables.

Table 5. Regression Model 1

\begin{tabular}{|l|c|c|c|c|c|}
\hline \multirow{2}{*}{$\begin{array}{c}\text { Dependent } \\
\text { Variable } P U\end{array}$} & \multicolumn{2}{|c|}{ Unstandardized Coefficients } & $\begin{array}{c}\text { Standardized } \\
\text { Coefficients }\end{array}$ & \multirow{2}{*}{ t-value } & Sig. \\
\cline { 2 - 4 } & $\mathrm{B}$ & Std. Error & Beta & & \\
\hline (Constant) & $.693^{* *}$ & .284 & & 2.444 & .016 \\
\hline$P W$ & $.379^{*}$ & .062 & .398 & 6.110 & .000 \\
\hline$T F$ & $.274^{*}$ & .062 & .255 & 4.457 & .000 \\
\hline$W P$ & $.100^{* *}$ & .044 & .119 & 2.258 & .025 \\
\hline$P P$ & $.082^{* * *}$ & .048 & .095 & 1.702 & .091 \\
\hline$E A$ & $-.135^{* *}$ & .053 & -.156 & -2.566 & .011 \\
\hline F-Statistics & 53.132 & & $\mathrm{R}^{2}$ & 0.610 & \\
\hline P-Value & $0.000^{*}$ & & Adjusted $\mathrm{R}^{2}$ & 0.598 & \\
\hline D-Watson & 2.048 & & & \\
\hline * & $* *$ and ${ }^{* * *}$ show significant at $1 \%, 5 \%$ and $10 \%$ respectively. & \\
\hline
\end{tabular}

The result of the regression equation 2 is presented in Table 6. The results show that paper usage is the significant determinant of paper wastage and results are statistically significant at $1 \%$ level. The positive and statistically significant value of beta of paper wastage and paper usage as an independent variable in two different equations indicate that there is a bi-directional causality between the two variables. Employee's awareness has an adverse 
relationship with paper wastage and results are significant at $1 \%$ confidence level. Technical factors have a positive relationship with the paper wastage but the result is not statistically significant. Workplace environment and personal preferences have a positive and significant relation with paper wastage at $10 \%$ level. The coefficient of determination and adjusted coefficient of determination shows that more than $54 \%$ variation is explained by the independent variables in the model. The diagnostic tests favor the robustness of the model. The significant value of F-Statistics indicates that the model is the best fit. The Durbin-Watson states show that the model is free from autocorrelation.

Table 6. Regression Model 2

\begin{tabular}{|l|c|c|c|c|c|}
\hline \multirow{2}{*}{$\begin{array}{c}\text { Dependent } \\
\text { Variable } P W\end{array}$} & \multicolumn{2}{|c|}{ Unstandardized Coefficients } & $\begin{array}{c}\text { Standardized } \\
\text { Coefficients }\end{array}$ & \multirow{2}{*}{ T } & Sig. \\
\cline { 2 - 4 } & $\mathrm{B}$ & Std. Error & Beta & & \\
\hline (Constant) & $.959^{*}$ & .315 & & 3.048 & .003 \\
\hline$T F$ & .071 & .073 & .063 & .981 & .328 \\
\hline$W P$ & $.088^{* * *}$ & .050 & .100 & 1.759 & .080 \\
\hline$P P$ & $.091^{* * *}$ & .054 & .101 & 1.688 & .093 \\
\hline$E A$ & $-.198^{*}$ & .058 & -.218 & -3.416 & .001 \\
\hline$P U$ & $.475^{*}$ & .078 & .453 & 6.110 & .000 \\
\hline F-Statistics & $42.546^{*}$ & & $\mathrm{R}^{2}$ & 0.556 & \\
\hline P-Value & 0.000 & & Adjusted $\mathrm{R}^{2}$ & 0.543 & \\
\hline D-Watson & 2.116 & & & \\
\hline *, ** and ${ }^{* * *}$ show significant at $1 \%, 5 \%$ and $10 \%$ respectively. \\
\hline
\end{tabular}

\subsection{Calculating the impact of paper consumptions on environment}

To assess the negative impact of paper usage and paper wastage on the operating cost of the organization and environment, we used standard formulas to quantify the impact. One ream of paper containing 500 pages of 80 gm paper approximately cost $1.5 \mathrm{OMR}$. To produce one ton of paper, 24 large size trees are cut, 5,690lbs carbon dioxide gas is emitted, $11,134 \mathrm{KHh}$ energy is consumed, 19,075 gallons of water is wasted and 2,278 lbs solid waste is produced (Abramovitz \& Ashley, 1999; Standard Chartered bank, 2010; Mueller, 2001; Repaper Project (n.d.); FAO, 1997). Table 7 shows total cost of paper consumed during one year and the impact of paper consumption on environment of the three selected education institutions in Dhofar region of Oman using the standard formulas.

The three institutions in Dhofar region used 5,200 reams (13 tons) of the 80 gm paper. The cost of the paper consumed in one year by the three institutions was 7,800 OMR. The paper used by the institutions was manufactured by cutting about 312 trees, 73,970 Ibs of $\mathrm{CO}_{2}$ gas was emitted, $144,742 \mathrm{KWh}$ energy was consumed, 29,614 lbs of solid waste was produced and 247975 gallons of water was wasted. 
Table 7. Impact of 5,200 reams (13 tons) of Paper used by three Selected Educational Institutions in Dhofar Region of Oman in one year $(\mathrm{I}$ OMR $=2.60$ US $\$$ )

\begin{tabular}{|c|c|c|c|c|c|c|}
\hline \multirow{3}{*}{$\begin{array}{l}\text { Quantity of } \\
\text { Office Paper } \\
\text { Used } \\
\text { (A4 and } 80 \\
\text { grams) }\end{array}$} & \multicolumn{6}{|c|}{ Impact } \\
\hline & Cost & & & Environment & & \\
\hline & $\begin{array}{c}\text { Total Cost } \\
@ 1.5 \text { OMR } \\
\text { per ream }\end{array}$ & $\begin{array}{c}\text { Trees } \\
\text { Required @ } \\
24 \text { per ton }\end{array}$ & $\begin{array}{c}\mathrm{CO}_{2} \\
\text { Emission @ } \\
\text { 5,690 lbs per } \\
\text { ton }\end{array}$ & $\begin{array}{l}\text { Energy Con- } \\
\text { sumed @ } \\
11,134 \mathrm{KWh} \\
\text { per ton }\end{array}$ & $\begin{array}{l}\text { Solid Waste } \\
@ 2278 \mathrm{Ib} \\
\text { per ton }\end{array}$ & $\begin{array}{l}\text { Water Waste } \\
@ 19,075 \text { gal- } \\
\text { lon per ton }\end{array}$ \\
\hline $\begin{array}{l}5,200 \text { reams } \\
\text { (13 tons) } \\
\text { (5.2 reams / } \\
2600 \text { paper } \\
\text { per person / } \\
\text { year) }\end{array}$ & 7,800 & 312 & 73,970 & 144,742 & 29,614 & 247975 \\
\hline
\end{tabular}

52,00 reams $=5,600,000$ pages $=13,000 \mathrm{KG}=13$ tons $=28,660 \mathrm{Ibs}$.

\subsection{Calculating the saving impact of paper}

There are many IT related tips/formulas identified by practitioners to reduce paper consumption in offices. Standard formulas from Mueller (2001) have been used to calculate paper saving possibilities in the three higher educational institutions of Dhofar Region, Oman. For example, $30 \%$ saving is possible by using both sides of paper for print purpose. Similarly, the efficient margin of 0.75 can save $4.75 \%$ of paper. Moreover, the use of line space of 0.9 and font size of 11.5 can save $5 \%$ of paper. By adopting these standard formulas, the saving impact of paper is calculated in the following Table 8 .

Table 8. Saving Impact of 5,200 reams (13 tons) of Paper used by three Selected Institutions in Dhofar Region in one year after Applying IT and Non-IT Tips

\begin{tabular}{|l|c|c|c|c|c|c|c|}
\hline \multirow{2}{*}{$\begin{array}{c}\text { Tips for efficient } \\
\text { use of paper }\end{array}$} & $\begin{array}{c}\text { Paper } \\
\text { (ream) }\end{array}$ & $\begin{array}{c}\text { Cost } \\
(\mathrm{OMR})\end{array}$ & $\begin{array}{c}\text { Trees } \\
(\text { no. })\end{array}$ & $\begin{array}{c}\mathrm{CO}_{2} \\
\text { Emission } \\
(\mathrm{Ibs})\end{array}$ & $\begin{array}{c}\text { Energy } \\
(\mathrm{KWh})\end{array}$ & $\begin{array}{c}\text { Solid } \\
\text { Waste } \\
\text { (Ibs) }\end{array}$ & $\begin{array}{c}\text { Water } \\
\text { Waste } \\
\text { (gallon) }\end{array}$ \\
\hline $\begin{array}{l}\text { Printing both Sides } \\
\text { (30\% saving) }\end{array}$ & 1560 & 2340 & 93.6 & $22,191.0$ & $43,422.6$ & 8884.2 & $74,392.5$ \\
\hline $\begin{array}{l}\text { Efficient Margin } \\
(0.75)(4.75 \% \text { sav- } \\
\text { ing) }\end{array}$ & 247 & 370.5 & 14.82 & $3,513.56$ & $6,875.25$ & 1406.67 & $11,778.81$ \\
\hline $\begin{array}{l}\text { Line Space (0.9) } \\
\text { (5\% saving) }\end{array}$ & 260 & 390 & 15.6 & $3,698.5$ & 7237.1 & 1480.7 & 12398.75 \\
\hline $\begin{array}{l}\text { Font Size (11.5) } \\
\text { (5\% saving) }\end{array}$ & 260 & 390 & 15.6 & $3,698.5$ & 7237.1 & 1480.7 & 12398.75 \\
\hline Total Savings & 2,327 & $3,490.5$ & 139.62 & $33,101.58$ & $64,772.05$ & $13,252.27$ & $110,968.81$ \\
\hline
\end{tabular}


By efficient use of paper, a significant amount of paper can be saved. By prudent use of printing commands such as printing on both sides of paper, efficient margin, line spacing and font size 2,327 reams of paper (5.82 tons) can be saved. As a result, 3,490.5 OMR can be saved which is about $44.8 \%$ of the total paper cost, 139.62 trees $(44.8 \%)$ can be saved, $33,101.58 \mathrm{lbs}$ of $\mathrm{CO}_{2}$ reduction (44.8\%), 64,7720.45KWh energy (44.8\%) can be saved, 213,252.27 Ibs solid waste $(44.8 \%)$ can be reduced and $110,968.81$ gallons of water $(44.8 \%)$ can be saved. This is just for three organizations with 1044 employees.

\section{Discussion and recommendations}

The results of the survey show that on average an employee in the educational institutions of Dhofar region of the Sultanate of Oman uses 15 pages per week and about 5 pages are wasted. The research findings suggest that (i) paper wastage, (ii) technical factors, (iii) workplace environment, (iv) personal printing preferences and (v) lack of awareness are among the most important factors which induce excessive paper usage. Technical problems in printing papers are malfunctioning of the printing machines, unfamiliar printing machines and unintended printing commands which result in excessive paper usage. By appropriate training of the employees to use the printing machines and timely repair and maintenance of the office equipment can significantly reduce the paper wastage and usage. In the survey, about $81.8 \%$ of the respondents agreed that training would help to improve paper conservation and about $67.1 \%$ want to attend a training program for the efficient use of paper. The workplace environment is another significant factor causing the excessive use of paper. Insecure work environment and organizational politics cause people to print documents and other material for their personal record to avoid future problems. By providing the cordial working environment and employees' training to respect the privacy of other co-workers in addition to prudent HR policies can contribute to the reduction in the paper usage. Personal printing preferences cause the excessive printing due to lack of knowledge about the impact of various printing settings on the consumption of paper and resultantly environmental degradation. If the proper margin, prudent line spacing and double-sided printing are used, a significant amount of paper can be saved. The results of over-consumption of paper due to personal printing preference is consisted with the results of a survey conducted by Kasavel (2013). The awareness about the impact of paper usage on the environment and cost is another factor which causes unwise paper consumption. A small effort to create awareness and proper training can greatly contribute to the optimal usage of paper. Optimal use of paper can greatly contribute to the reduction of operating cost of the organizations as well as significant reduction in environmental degradation.

\section{Conclusions}

This paper aims to investigate the factors potentially responsible for the excessive use of paper and wastage of paper in the workplace and estimate its impact on the environment and economic cost of the organizations in Dhofar region of Sultanate of Oman. A personally administered survey of the educational institutions was conducted to obtain the data related 
to the variables under the consideration from the academic and administrative staff of the educational institutions. The research findings show that technical factors, workplace environment, printing preferences and lack of awareness are the main causes of excessive printing and paper wastage. The three Higher Educational Institutions in Dhofar region have used 5,200 reams (13 tons) of the 80 gm A4 size paper in 2015. The economic cost (only paper cost) of the paper was 7,800 OMR (20,280 US\$). The environmental impacts estimated are: cutting of 312 trees, 73,970 Ibs of $\mathrm{CO}_{2}$ gas emission, 144,742 KWh of energy consumption, solid waste produced 29,614 lbs of and 247975 gallons of water was wasted. By changing the printing preferences and creating awareness, a significant amount of economic and environmental resources can be saved to the tune of $44.8 \%$.

The results show that an efficient and wise utilization of paper is an important component of environmental sustainability and cost reduction. However, policy related to printing in workplaces is lacking in most of the organizations. To minimize paper consumption, each organization can develop their own policy for paper use and printing. It would be more effective for each institution to devise a standard paper saving settings for paper use. Similarly, there is a lack of awareness among the office workers regarding the impact of excessive printing on the organizations' cost and the environment. It is necessary to make them aware to the causes of excessive use of paper, cost impact and environmental impact. Employee awareness of the amount of paper they used for copying and printing and the amount of money spent on paper and printing will change the attitude of employees of overusing paper. Training workers how to minimize paper use is also essential for the organization. Similarly, technical know-how about printer use is important to reduce misprinting. Organizations can help protect the climate by using paper more efficiently and avoiding wasteful.

The paper developed a theoretical background discussion on the basis of empirical research data of paper consumption and wastage in various organizations/countries worldwide. Overall the paper contributes to the current knowledge of sustainability by analyzing current practices related to paper consumption. This paper is limited to the four factors related to overconsumption of paper in offices i.e. technical factors, workplace environment, employees' personal preferences, employee's awareness and training. On the impact side of paper consumption, only environmental and economic cost is included. The researchers can include other variables such as organization policies, ease of using printing technology etc. Similarly, the impact of paper on organization efficiency can be included in the other studies. This paper will help organizations to analyze their current practices, policies and take practical action to reduce environmental impact and economic costs by improving the use of organization resources.

\section{Author contributions}

Iqtidar conceived the study and he is responsible for the design and development of the paper and he wrote the first draft. Nasser was responsible for data collection. Sohail was responsible for data analysis and interpretation. 


\section{Disclosure statement}

We hereby declare that there is no competing financial, professional, or personal interest from other parties.

\section{References}

Andrés, L., Zentner, A., \& Zentner, J. (2014). Measuring the effect of internet adoption on paper consumption. Policy Research Working Paper N. 6965, South Asia Region, Sustainable Development Department, World Bank Group. https://doi.org/10.1596/1813-9450-6965

AL-Qahtani, S. H. (2012). The paperless organization: improved processes and reduction in paper usage through wider use of electronic documents and tablet computers (Thesis, Master of Science (MSc)). University of Waikato, Hamilton, New Zealand. Retrieved from http://hdl.handle.net/10289/7023

Abramovitz, J., \& Ashley, M. (1999). Paper cuts: recovering the paper landscape (pp. 13-14). Worldwatch Paper 149.

Egebark, J., \& Ekström, M. (2013). Can indifference make the world greener? IFN Working Paper No. 975, Research Institute of Industrial Economics, Sweden. Retrieved from file:///C:/Users/Administrator/Downloads/SSRN-id2324922.pdf

Federal Electronic Challenges. (2012). Reducing paper and printer ink usage. Federal Electronic Challenges, Environmental Protection Agency, USA. Retrieved from http://www.epa.gov/fec

Fujitsu. (2001). AIIM International ECM road show. Sacramento, CA. September 10, 2001.

FAO. (1997). State of the world's forests 1997. Food and Agriculture Organization of the United Nations (FAO), Rome, 1997.

Hujala, M. (2011, January). The role of information and communication technologies in paper consumption. International Journal of Business Information Systems, 7(2), 121-135. https://doi.org/10.1504/IJBIS.2011.038507

Hesseldahl, A. (2008, May 27). The new push to get rid of paper. Business Week.

Jonkute, G. (2015). The consumers' approach to sustainable consumption and production: a case study in Lithuania. Environmental Research, Engineering and Management, 71(4), 28-46.

Jenkin, T. A., Webster, J., \& McShane, L. (2011). An agenda for "Green" information technology and systems research. Information and Organization, 21(1), 17-40.

https://doi.org/10.1016/j.infoandorg.2010.09.003

Kazanci, Z. (2015). University students' preferences of reading from a printed paper or a digital screen a longitudinal study. International Journal of Culture and History, 1(1), 50-53.

Krishnan, S., \& Subramanian, N. (2015). Evaluating carbon-reducing impact of document management systems. 7th Annual IEEE Green Technologies Conference (pp. 88-94). New Orleans, LA, 2015. https://doi.org/10.1109/GREENTECH.2015.32

King, K., \& Toland, J. (2014). iPads and the paperless office: the impact of tablet devices on paper consumption in higher education. Journal of Applied Computing and Information Technology, 18(1). Retrieved from http://www.citrenz.ac.nz/jacit/JACIT1801/2014King_PaperlessOffice.html

Kasavel, K. (2013). Managing paper use in the office: conducting a paper use survey. Retrieved from http://www.urbanearth.co.za/articles/managing-paper-use-office-conducting-paper-use-survey

Mukete, B., Sun, Y., Zama, E., \& Monono, S. K. (2016). Paper consumption and environmental impact in an emerging economy. Journal of Energy, Environmental \& Chemical Engineering, 1(1), 13-18.

Moberga, A., Johanssonb, M., Finnvedena, G., \& Jonssonc, A. (2010). Printed and tablet e-paper newspaper from an environmental perspective - a screening life cycle assessment. Environmental Impact Assessment Review, 30(3), 177-191. https://doi.org/10.1016/j.eiar.2009.07.001 
McCool, C. (2008). How to reduce printing costs by 17\%: a guide to doing well and doing good by printing less, a green print technologies. Portland White Paper. Retrieved from www.printgreener.com

Mueller. (2001). Mueller Policy Paper \#1: Reduce Standard Margin Settings. Penn State University, USA. Retrieved from file://C:/Users/Iqtidar/Desktop/2016/TRC\%20project/ IT\%20to\%20save\%20environment/mueller_policy_1update.pdf

McCormack, N. (2011). Mission impossible? The future of "paperless" library operations. Library Management, 32(4/5), 279-289. https://doi.org/10.1108/01435121111132284

Minnesota Pollution Control Agency. (2016). Become a paperless office. Retrieved from http://www. reduce.org/

Niinimäki, K., \& Hassi, L. (2011). Emerging design strategies in sustainable production and consumption of textiles and clothing. Journal of Cleaner Production, 19(16), 1876-1883. https://doi.org/10.1016/j.jclepro.2011.04.020

Paperless Project. (2013). Facts about paper: the impact of consumption. Retrieved from http://www. thepaperlessproject.com/

Preton. (2010). Environmental issues associated with toner and ink usage. Preton Ltd, White Paper.

Peters, G. (2003). A Society Addicted to Paper - The Effect of Computer Use on Paper Consumption. School of Computing Science, Simon Fraser University Vancouver, B.C., Canada V5A 1S6.

Penn State University. (2000). Penn State Indicator Report 2000. Penn State University, USA.

Planet, A. (2008). The role of e-billing in reducing the environmental impacts of paper consumption. Planet Ark Report January 24, 2008.

Ranko, S., Berislav, B., \& Antun, S. (2008, 19-21 June). New ways in manufacturing engineering, document management system as source of competitive advantage. Prešov, Slovak Republic.

Repaper Project. (n.d.). Recovering and discovering a source. National Wildlife Federation, Merrifield VA 22116-1583, USA. Retrieved from http://www.wastexchange.org/upload_publications/OfficePaperRecyclingGuide.pdf

SC Technology Group. (2015). 3 Must - have technologies to reduce paper consumption. SC Technology Group. Retrieved from http://www.sctechnologygroup. com.au/3-must-have-technologies-toreduce-paper-consumption/

Sarantis, H. (2002). Business guide to paper reduction: a step-by-step plan to save money by saving paper, forest ethics. Retrieved from http://sustainability.tufts.edu/wp-content/uploads/BusinessGuidetoPaperReduction.pdf

Sellen, A. J., \& Harper, R. (2002). The myth of the paperless office. Cambridge MA: The MIT Press.

Sharma, B. K. (2014, 13-14 August). Impact of paper industry on environment: a case study of the Nagaon Paper Mill. Paper presented in International Conference on Trends in Economics, Humanities and Management (ICTEHM'14). Pattaya (Thailand).

Sophia, B. M. (2013). Sustainable paper consumption: exploring behavioural factors. Social Science, 2, 270-283. https://doi.org/10.3390/socsci2040270

Soskolne, C. L., \& Sieswerda, L. E. (2010). Cancer risk associated with pulp and Paper Mills: a review of occupational and community epidemiology. Journal of Health Promotion and Chronic Disease Prevention in Canada: Research, Policy and Practice, 29 (Supplement 2).

Smith, R. E. (2011). The environmental sustainability of paper. Graduate Studies Journal of Organizational Dynamics, 1(1), 1-18.

Standard Chartered Bank. (2010). Reducing and eliminating paper consumption: a best practice guide for corporate offices (1rst ed.), May 2010. Standard Chartered Bank (China) limited, Shanghai, China.

Susanty, W., Thamrin, T. E., \& Cucus, A. (2012, 20-21 June). Document management system based on paperless. $1^{\text {st }}$ International Conference on Engineering and Technology Development (ICETD 2012). 
Universitas Bandar Lampung, Lampung, Indonesia.

Sustainability Victoria. (2011). Save paper, sustainability Victoria. Retrieved from sustainability.vic.gov. $\mathrm{au}$

Sumathi, S., \& Hung, Y. (2006). Chapter in Hand book of industrial and hazardous wastes treatment (2nd ed.). Revised and expanded. L. K. Wang, Y-T. Hung, H. H. Lo, \& C. Yapijakis (Eds.) (pp. 469551). CRC Press.

Throne, H., Sto, E., \& Strandbakken, P. (2007). The role of consumption and consumers in zero emission strategies. Journal of Cleaner Production, 15.

Tam, P. (2004). The paper trail: cost cutters have their sights on a new target: the office printer. The Wall Street Journal, R4, September 13, 2004.

Thompson, G., Swain, J., Kay, M., \& Forster, C. F. (2001). The treatment of pulp and paper mill effluent: a review. Bioresource Technology, 77(3), 275-286. https://doi.org/10.1016/S0960-8524(00)00060-2

Upstate Medical University. (2016). Think green, sustainability initiative. Upstate Medical University, New York. Retrieved from http://www.upstate.edu/green/pdf/tg-news/tg-news-summer-2016.pdf

World Health Organization. (2016). Dioxins and their effects on human health. Retrieved from http:// www.who.int/en/news-room/fact-sheets/detail/dioxins-and-their-effects-on-human-health

WWF. (2015). World wide funds. Retrieved from savepaper@wwfdcp.org

Webster, M. (2012). Bridging the information worker productivity gap: new challenges and opportunities for IT. International Data Corporation, 5 Speen Street Framingham, MA 01701 USA.

York, R. (2006). Ecological paradoxes: William Stanley Jevons and the paperless office. Human Ecology Review, 13(2), 143. 